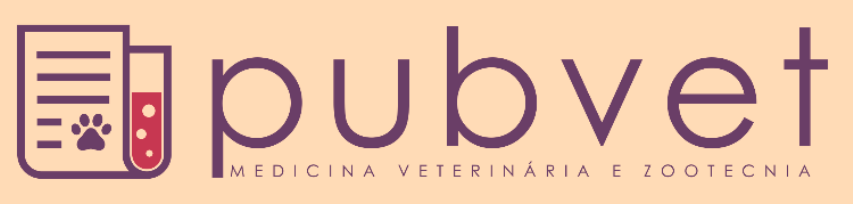

https://doi.org/10.31533/pubvet.v14n4a557.1-6

\title{
Sensibilidade de Staphylococcus aureus aos antimicrobianos usados no tratamento da mastite bovina: Revisão
}

\author{
Brenner Frederico Carvalho Alves ${ }^{10}$, Ana Júlia Silveira Chaves ${ }^{1}$, Natâne Flávia Vieira ${ }^{10}$, \\ Glauco Vinício Chaves ${ }^{2}{ }^{\circ}$, Patrícia Maria de França ${ }^{3}{ }^{\circ}$, Amanda Soriano Araújo Barezani ${ }^{2}{ }^{\circ}$, \\ Paulo Henrique Araújo Soares ${ }^{* *}$
}

${ }^{I}$ Discente do curso de Medicina Veterinária do Instituto Federal de Minas Gerais - Campus Bambuí.

${ }^{2}$ Professor(a) do curso de Medicina Veterinária do Instituto Federal de Minas Gerais - Campus Bambuí.

${ }^{3}$ Professora substituta do curso de Zootecnia do Instituto Federal de Minas Gerais - Campus Bambuí.

${ }^{4}$ Professor do curso de Medicina Veterinária da Faculdade Pitágoras - Divinópolis.

*Autor para correspondência, E-mail:fr.brenner@outlook.com

\begin{abstract}
Resumo Visto como um dos principais problemas econômicos e sanitários nas propriedades brasileiras, a mastite bovina mostra-se como uma doença de grande prevalência dentre os animais de produção. Um dos principais gargalos referente a tal enfermidade é a resistência antimicrobiana, em especial, quando a etiologia está associada a bactéria Staphylococcus aureus. Nessa perspectiva, o presente trabalho tem por objetivo discorrer sobre o perfil de resistência de $S$. aureus e alguns fatores envolvidos. Para tal, os dados foram apresentados na forma de uma revisão narrativa da literatura, tendo como embasamento estudos indexados as plataformas: Portal de Periódicos CAPES-MEC e SciELO. Foi verificado na pesquisa bibliográfica um acentuado perfil de resistência antimicrobiana do $S$. aureus, sendo os antibióticos menos eficazes a Penicilina e Ampicilina e o de melhor eficácia no tratamento a Cefalotina. Outros dados compilados foram: o de que animais mais velhos possuem maior chance de apresentarem resistência aos tratamentos antimicrobianos e de que em algumas situações o custo-benefício do tratamento de mastite subclínica por $S$. aureus não traz retornos econômicos, mas somente na melhoria da qualidade do leite. Nesse contexto, ressalta-se a importância de novas pesquisas para traçar a evolução da resistência antimicrobiana do S. aureus, bem como fomentar atividades extencionistas para educação no campo sobre os corretos procedimentos terapêuticos da mastite bovina.
\end{abstract}

Palavras chave: Antimicrobianos, resistência, Staphylococcus aureus

\section{Sensitivity of Staphylococcus aureus to antimicrobials used to treat bovine mastitis: Review}

\begin{abstract}
Seen as one of the main economic and health problems in Brazilian properties, bovine mastitis shows as a disease of high prevalence among farm animals. One of the main bottlenecks related to this disease is antimicrobial resistance, especially when the etiology is associated with a Staphylococcus aureus bacterium. From this perspective, this paper aims to discuss the resistance profile of $S$. aureus and some factors involved. For this, the data were presented in the form of a narrative review of the literature, based on studies indexed as platforms: Portal of Journals CAPES-MEC and SciELO. An antimicrobial resistance profile of $S$. aureus was selected in the literature search, being the least used antibiotics in Penicillin and Ampicillin and the best use in the treatment of cephalothin. Other data compiled were that older animals are more likely to have antimicrobial resistance and that in some situations or the benefit of treatment of
\end{abstract}


subclinical mastitis by $S$. aureus does not bring economic returns, but only in the quality to make milk. In this context, highlight the importance of new research to track the evolution of antimicrobial resistance of $S$. aureus, as well as promote extensive activities for education in the field on the correct therapeutic procedures of bovine mastitis.

Keywords: Antimicrobials. Resistance. Staphylococcus aureus

\title{
Sensibilidad de Staphylococcus aureus a los antimicrobianos utilizados para tratar la mastitis bovina: revisión
}

\begin{abstract}
Resumen Visto como uno de los dos principales problemas económicos y de salud de las granjas brasileñas, la mastitis bovina es una enfermedad altamente prevalente entre los animales de granja. Uno de los dos principales cuellos de botella con respecto a esta enfermedad y la resistencia a los antimicrobianos, especialmente cuando la etiología está asociada con la bacteria Staphylococcus aureus. De ese modo, este trabajo tiene como objetivo reseñar el perfil de resistencia de $S$. aureus y algunos factores involucrados. Para esto, las informaciones son presentadas en forma de una revisión narrativa de literatura, basada en estudios indexados a plataformas: Portal de periódicos CAPES-MEC y SciELO. Fue verificado un marcado perfil de resistencia antimicrobiana de $S$. aureus, siendo antibióticos menos efectivos la penicilina y la ampicilina y una mejor eficacia en el tratamiento de cefalotina. Otros datos recopilados fueron: que animales más viejos tienen más chances de presentar resistencia a los tratamientos antimicrobianos y que, en algunas situaciones los costos-beneficios de del tratamiento subclínico de la mastitis por $S$. aureus, no genere un retorno económico, mas solamente en la mejora de la calidad de la leche. En este contexto, la importancia de nuevas investigaciones para evolucionar la resistencia a los antimicrobianos de $S$. aureus, así como para promover actividades de extensión para la educación a campo sobre los procedimientos terapéuticos correctos de la mastitis bovina.
\end{abstract}

Palabras clave: Antimicrobianos, resistencia. Staphylococcus aureus

\section{Introdução}

A mastite bovina é uma doença de alta prevalência nos rebanhos leiteiros do Brasil. Tal enfermidade é caracterizada pela inflamação da glândula mamária a partir de um dano biológico, físico ou químico, que gera como consequência: reduções nos componentes do leite e alterações no tecido glandular (Oliveira et al., 2009). Neste contexto, é imprescindível dar atenção para tal patologia, haja vista, que causa impacto tanto no campo econômico quanto no que se refere à saúde pública. No campo econômico, os prejuízos estão relacionados aos seguintes fatores: redução na produção de leite; gasto com medicamentos; perdas com descarte do leite; custos com serviços veterinários; manejo extra de funcionários para o tratamento; redução na qualidade dos produtos finais; e consequentemente descarte prematuro de vacas (Oliveira Júnior et al., 2012).

Em relação à saúde pública, destacam-se o uso indiscriminado e, muitas vezes, incorretos de antimicrobianos. Como consequência tem um aumento nas taxas de resistência microbiana, que promovem riscos tanto a saúde humana quanto animal em um futuro tratamento (Costa et al., 2013).

Nessa perspectiva, o presente estudo tem por objetivo realizar uma revisão narrativa de literatura, através da apresentação de um compilado de pesquisas que versam sobre a suscetibilidade a antimicrobianos do microrganismo Staphylococcus aureus, bem como apresentar aspectos relacionados a mastite bovina proveniente dessa etiologia.

\section{Mastite bovina}

A mastite bovina é uma enfermidade caracterizada pela inflamação da glândula mamária, em decorrência da ação de agentes biológicos, físicos ou químicos, sendo considerada uma doença plurietiológica e multifatorial. Tal enfermidade causa grandes reduções nos componentes do leite, bem como alterações no 
tecido glandular. No Brasil a mastite é tida como um dos maiores desafios da indústria láctea, haja vista, sua alta prevalência nos rebanhos leiteiros (Burton \& Erskine, 2003; De Vliegher et al., 2012).

Essa doença pode se apresentar de duas formas, denominadas: mastite clínica e subclínica. A primeira forma é aquela encontrada em animais que manifestam a sintomatologia clínica da doença, ou seja, alterações macroscópicas (edema do úbere, dor, "grumos no leite", endurecimento e aumento de temperatura). Já a segunda forma, é aquela que se apresenta de maneira assintomática, manifestando apenas alterações na composição do leite, como por exemplo, aumento no número de células somáticas (CCS) e das concentrações de cloro e sódio. É possível verificar também diminuição nos teores de lactose, caseína e gordura (Dias, 2007).

Além disso, a mastite pode ser classificada de acordo com os patógenos envolvidos na etiologia da doença, podendo ser: mastite contagiosa ou ambiental. Os agentes da mastite contagiosa são microrganismos presentes na microbiota do teto e que se proliferam na glândula mamária quando as condições são propícias, neste sentido, sua transmissão pode ocorrer de teto para teto durante o processo da ordenha. Os principais microrganismos contagiosos são: Staphylococcus aureus, Streptococcus agalactiae, Mycoplasma species e Corynebacterium bovis (Acosta et al., 2016).

Já a mastite ambiental tem sua etiologia relacionada com microrganismos presentes nos recintos em que vive o animal. Os mais frequentes agentes ambientais são: Escherichia coli, Streptococcus dysgalactiae, Streptococcus uberis, Streptoccous bovis, Enterococcus faecium e Enterococcus faecalis (Kulkarni \& Kaliwal, 2013). Segundo Santos et al. (2007) aproximadamente 95\% das mastites de origem infecciosa no Brasil são decorrentes dos patógenos: Streptococcus agalactiae, Staphylococcus aureus, Streptococcus uberis e coliformes.

A conduta terapêutica frente a um quadro de mastite se apresenta no uso de antimicrobianos que podem ser administrados por via intramamária ou via sistêmica, podendo em alguns casos associar as duas vias. As principais bases farmacológicas utilizadas no tratamento da mastite são: penicilinas; cefalosporinas; tetraciclinas; macrolídeos e lincosaminas; polimixinas; aminoglicosídios; sulfonamidas; quinolonas (Spinosa et al., 2002).

Noel et al. (2016) mostram que o uso indiscriminado de antimicrobianos para o tratamento de vacas com mastite pode gerar seleção de patógenos multirresistentes e desencadear resíduos no leite e derivados, fomentando assim o risco à saúde pública.

\section{Resistência antimicrobiana}

A resistência aos antimicrobianos dá-se por meio de administração de níveis sub terapêutico de antibióticos ou promotores de crescimento adicionados na alimentação de animais de produção, como resultado, é ocasionado à resistência em cepas da bactéria e por aspectos reprodutivos são disseminada tal características para as novas unidades formadoras de colônia (Souza et al., 2016). As bactérias adquirem resistência aos antimicrobianos por mecanismos de alteração dos genes (mutação) ou quando microrganismos resistentes fazem conjugação e transferência de plasmídeos a bactérias não resistentes (Santos et al., 2006). Barberio et al. (2002) fazem um alerta para o uso inadequado de antimicrobianos em animais que estão em um quadro de mastite. Segundo os autores, tais procedimentos terapêuticos muitas vezes são realizados de forma incorreta - seja por sub dosagem ou não cumprimento das doses recomendadas do agente antimicrobiano - o que gera cepas de microrganismos resistentes. Nesse sentido, cepas de microrganismos resistentes podem ser disseminados a outros animais, gerando ineficiência em tratamentos futuros.

O uso de aditivos antimicrobianos na produção animal é autorizado pelo Ministério da Agricultura, Pecuária e Abastecimento (MAPA) devido sua influência direta na produção animal por atingir seu pico produtivo em concomitância diminuir o consumo. Por conseguinte, esta utilização de antibióticos na alimentação animal implica na resistência bacteriana levando a alterações no processo saúdedoença dos animais submetidos, nos mostrando um resultado não tão satisfatório (Baptista, 2013; Costa \& Silva Júnior, 2017). 


\section{Perfil de resistência do Staphylococcus aureus e aspectos relacionados}

O patógeno Staphylococcus aureus são pertencentes ao grupo dos cocos, ou seja, bactérias de forma esférica e por sua vez organizam-se em cachos de uva, são caracterizados pela coloração amarelada de suas colônias e são anaeróbicos facultativos, sendo assim, são capazes de realizar suas atividades metabólicas tanto em ambientes com a presença de oxigênio quanto na ausência deste gás (Tortora et al., 2017).

Santos et al. (2007) mostraram o S. aureus como um grande resistente a antimicrobianos, prova disto, a resistência de cepas da bactéria na antimicrobiano terapia com sulfanilamida como descoberto Gerard Domagk (bacteriologista e patologista alemão) em meados de 1932, fato este que persiste até a atualidade, pois, novas cepas de S. aureus resistentes aos antibióticos estão surgindo. Ademais, como sendo um dos microrganismos que tem por característica o seu grande potencial de causar infecções em animais, o Staphylococcus aureus demanda atenção para sua virulência e por ser um patógeno causador de uma gama grande de doenças animais.

Ao analisar o índice de resistência de Staphylococcus aureus aos antimicrobianos Noel et al. (2016) chegaram aos seguintes resultados: Penicilina (99,5\%), enrofloxacina (57\%), tetraciclina (56\%), ciprofloxacina (43\%), cefoxitina $(37,7 \%)$, oxaciclina $(26,1 \%)$, ceftriaxona $(21,7 \%)$, ampicilina+Sulbactam $(13,5 \%)$, azitromicina $(17,9 \%)$, eritromicina $(17,9 \%)$, gentamicina $(14,9 \%)$ e cefalotina (14,9\%). Já Costa et al. (2013) conduziram um estudo com 35 rebanhos leiteiros localizados em Minas Gerais que possuíam casos de mastite proveniente de Staphylococcus aureus. Os autores verificaram a partir dos testes de antibiograma, os seguintes índices de resistência: Polimixina B $(82,0 \%)$, ampicilina $(80,9 \%)$, penicilina $(80,5 \%)$, neomicina $(3,4 \%)$, gentamicina $(1,69 \%)$, ceftiofur $(0,40 \%)$, florfenicol $(0,40 \%)$, cefalotina $(0,28 \%)$, enrofloxacino $(0,26 \%)$. Em uma pesquisa realizada com rebanhos leiteiros de Pernambuco, foram verificados os seguintes índices de resistência antimicrobiana: Penicilina (95\%), Ampicilina (88\%), Gentamicina (18\%), Clindamicina (6\%), Tetraciclina (6\%), Eritromicina (4\%). Não foi averiguada amostras resistentes a cefalotina e enrofloxacino (Silva, 2012).

Santiago-Neto et al. (2014) avaliaram a influência da idade dos animais sobre o perfil de resistência aos antimicrobianos. Os pesquisadores constataram que o tempo de exposição aos patógenos e terapias errôneas possibilitam uma maior chance de proliferação do agente infeccioso sobre o úbere dos bovinos em razão da pressão de seleção. Isso foi demonstrado a partir do dado que vacas com três a quatro anos tiveram 13,7 vezes mais chances $\left(\mathrm{IC}_{95 \%} 1,4-130,2, \mathrm{P}=0,02\right)$ de possuir estafilococos coagulase-positivo multirresistentes quando comparadas as vacas de dois a três anos.

Beuron et al. (2014) realizaram um estudo sobre os fatores de risco associados com a resistência antimicrobiana de Staphylococcus aureus. A partir dos rebanhos analisados (com questionários aos produtores e analises microbiológicas) os pesquisadores indexaram os dados em um modelo final de regressão logística no qual foram verificados os seguintes aspectos de potencial risco a resistência antimicrobiana a Staphylococcus aureus: tratamento com ampicilina e penicilina e não envio de amostras de leite para cultura microbiológica e testes de suscetibilidade a antimicrobianos.

Quanto aos aspectos econômicos, Zafalon et al. (2007) avaliaram a relação custo-benefício do tratamento de vacas com mastite subclínica (causada por $S$. aureus). No estudo foi demonstrado que mesmo tratando os animais com taxas elevadas de gentamicina intramamária e obtendo alto índice de cura microbiológica, não houve aumento da produção de leite dos quartos tratados em comparação com os quartos sadios. Apesar de não ter surtido efeito na vertente financeira (receita), observou-se melhora da qualidade do leite, haja vista, que houve redução da CCS dos quartos mamários tratados.

\section{Considerações finais}

Com base nos dados descritos nessa revisão é possível inferir que o microrganismo Staphylococcus aureus vem se tornado resistente a vários antimicrobianos e seus impactos tanto do ponto de vista econômico, quanto da saúde pública devem ser considerados. Nesse contexto, ressalta-se a importância de contínuas pesquisas para mapear o perfil de susceptibilidade aos antimicrobianos do $S$. aureus, bem como estimular projetos extencionistas de conscientização dos produtores frente a tal problemática. 


\section{Referências bibliográficas}

Acosta, A. C., Silva, L. B. G., Medeiros, E. S., Pinheiro-Júnior, J. W., \& Mota, R. A. (2016). Mastites em ruminantes no Brasil. Pesquisa Veterinária Brasileira, 36(7), 565-573.

Baptista, M. G. F. M. (2013). Mecanismos de Resistência aos Antibióticos. In Ciências Farmacêuticas. Universidade Lusófona de Humanidades e Tecnologia.

Barberio, A., Gietl, H., \& Dalvit, P. (2002). In vitro" sensibilidade aos antimicrobianos de Staphylococcus aureus e coliformes isolados de mastite bovina na região de Veneto, Itália, no período de 1996-1999. Revta Napgama, São Paulo, 5(1), 10.

Beuron, D. C., Cortinhas, C. S., Botaro, B. G., Macedo, S. N., Gonçalves, J. L., Brito, M. A. V. P., \& Santos, M. V. (2014). Risk factors associated with the antimicrobial resistance of Staphylococcus aureus isolated from bovine mastitis. Pesquisa Veterinária Brasileira, 34(10), 947-952.

Burton, J. L., \& Erskine, R. J. (2003). Immunity and mastitis some new ideas for an old disease. Veterinary Clinics: Food Animal Practice, 19(1), 1-45.

Costa, A. L. P., \& Silva Júnior, A. C. S. (2017). Resistência bacteriana aos antibióticos e saúde pública: uma breve revisão de literatura. Estação Científica (UNIFAP), 7(2), 45-57.

Costa, G. M., Barros, R. A., Costa Custódio, D. A., Pádua Pereira, U., Figueiredo, D. J., \& Silva, N. (2013). Resistência a antimicrobianos em Staphylococcus aureus isolados de mastite em bovinos leiteiros de Minas Gerais, Brasil. Arquivos Do Instituto Biológico, 80(3), 297-302.

De Vliegher, S., Fox, L. K., Piepers, S., McDougall, S., \& Barkema, H. W. (2012). Invited review: Mastitis in dairy heifers: Nature of the disease, potential impact, prevention, and control. Journal of Dairy Science, 95(3), 1025-1040.

Dias, R. V. C. (2007). Principais métodos de diagnóstico e controle da mastite bovina. Acta Veterinária Brasílica, 1(1), 23-27.

Kulkarni, A. G., \& Kaliwal, B. B. (2013). Bovine mastitis: a review. International Journal of Recent Scientific Research, 4(5), 543-548.

Noel, C. C., Motta, F. S., Francisco, N. L. S. G., Almeida, N. R., \& Soares, L. C. (2016). Perfil de suscetibilidade antimicrobiana e produção de "slime" de isolados de Staphylococcus spp. provenientes de casos de mastite bovina na região sul-fluminense. Revista de Saúde, 7(1), 22-26.

Oliveira, A. A., Melo, C. B., \& Azevedo, H. C. (2009). Diagnóstico e determinação microbiológica da mastite em rebanhos bovinos leiteiros nos tabuleiros costeiros de Sergipe. Ciência Animal Brasileira, 10(1), 226-230.

Oliveira Júnior, M. B., Vanderlei, D. R., Moraes, W. S., Brandespim, D. F., Mota, R. A., Oliveira, A. A. F., Medeiros, E. S., \& Pinheiro Júnior, J. W. (2012). Fatores de risco associados à mastite bovina na microrregião Garanhuns, Pernambuco. Pesquisa Veterinária Brasileira, 32(5), 391-395.

Santiago-Neto, W., Machado, G., Paim, D. S., Campos, T., Brito, M. A. V. P., Cardoso, M. R. I., \& Corbellini, L. G. (2014). Relação da idade na presença de bactérias resistentes a antimicrobianos em rebanhos leiteiros no Rio Grande do Sul. Pesquisa Veterinária Brasileira, 34(7), 613-620.

Santos, A. L., Santos, D. O., Freitas, C. C., Ferreira, B. L. A., Afonso, I. F., Rodrigues, C. R., \& Castro, H. C. (2007). Staphylococcus aureus: visitando uma cepa de importância hospitalar. Jornal Brasileiro de Patologia e Medicina Laboratorial, 43(6), 413-423.

Santos, C. D. M., Leal, G. S., \& Rossi, D. A. (2006). Frequência e suscetibilidade a antimicrobianos de Staphylococcus spp isolados de leite de vacas com mastites recorrentes de rebanhos da região de Uberlândia-MG. Veterinária Notícias, 12(2), 83-88.

Santos, E. M. P., Brito, M. A. V. P., Lange, C., Brito, J. R. F., \& Cerqueira, M. M. O. P. (2007). Streptococcus e gêneros relacionados como agentes etiológicos de mastite bovina. Acta Scientiae Veterinariae, 35(1), 17-27.

Silva, E. R. (2012). Perfil de sensibilidade antimicrobiana in vitro de Staphylococcus aureus isolado de mastite subclínica bovina. Revista Brasileira de Saúde e Produção Animal, 13(3), 701-711.

Souza, M. M. S., Coelho, S. M. O., Coelho, I. C., Soares, B. S., Motta, C. C., Melo, D. A., Dubenczuk, F. C., Santiago, G. S., Pimenta, R. L., \& Marques, V. F. (2016). Resistência antimicrobiana em 
animais de produção: uma visão geral. Brazilian Journal of Veterinary Medicine, 38(Supl. 3), 6874.

Spinosa, H. S., Górniak, S. L., \& Bernardi, M. M. (2002). Farmacologia aplicada à medicina veterinária. Guanabara Koogan.

Tortora, G. J., Berdell, R. F., \& Christine, L. C. (2017). Microbiologia. Artmed.

Zafalon, L. F., Nader Filho, A., Oliveira, J. V, \& Resende, F. D. (2007). Mastite subclínica causada por Staphylococcus aureus: custo-benefício da antibioticoterapia de vacas em lactação. Arquivo Brasileiro de Medicina Veterinária e Zootecnia, 59(3), 577-585.

Recebido: 26 de novembro, 2019.

Aprovado: 3 de janeiro, 2020.

Publicado: 25 de maio, 2020.

Licenciamento: Este artigo é publicado na modalidade Acesso Aberto sob a licença Creative Commons Atribuição 4.0 (CC-BY 4.0), a qual permite uso irrestrito, distribuição, reprodução em qualquer meio, desde que o autor e a fonte sejam devidamente creditados. 